\title{
Isolamento de Gluconacetobacter spp. em diferentes tipos de solos
}

\author{
Carla Cristiane Rocha dos Santos ${ }^{(1)}$, Liamara Perin ${ }^{(1)}$, José Ivo Baldani(1) e Veronica Massena Reis ${ }^{(1)}$
}

${ }^{(1)}$ Embrapa Agrobiologia, Caixa Postal 74505, BR 465, Km 7, CEP 23851-970 Seropédica, RJ. E-mail: carlacristiane@hotmail.com.br, liaperin@yahoo.com.br, ibaldani@cnpab.embrapa.br, veronica@cnpab.embrapa.br

\begin{abstract}
Resumo - O objetivo deste trabalho foi o aprimoramento da técnica de imunocaptura para utilização em amostras de solo contendo altos teores de argila e sua aplicação no isolamento de estirpes de Gluconacetobacter diazotrophicus a partir de amostras de solo cultivado com cana-de-açúcar e café. A técnica de imunocaptura foi aplicada com sucesso no isolamento de bactérias de amostras de solo. A modificação do método de imunocaptura com $\mathrm{Al}_{2}\left(\mathrm{SO}_{4}\right)_{3}$ permitiu a sua aplicação em amostras de solo argiloso pela floculação da argila em suspensão. Este método mostrou-se efetivo no isolamento de $G$. diazotrophicus inoculada em amostras de solo arenoso e argiloso aos cinco dias após a inoculação. A sensibilidade máxima do método em isolar células de $G$. diazotrophicus mediante cultura pura foi de $10^{3}$ células $\mathrm{mL}^{-1}$. A modificação da técnica permitiu o isolamento de Gluconacetobacter spp. de amostras de solo colhidas a $50 \mathrm{~cm}$ das raízes de plantas de café, mas não de amostras de solo colhidas à mesma distância de plantas de cana-de-açúcar.
\end{abstract}

Termos para indexação: imunologia, ecologia, cana-de-açúcar, café, bactéria diazotrófica.

\section{Isolation of Gluconacetobacter spp. in different soil types}

\begin{abstract}
The objective of this work was to improve the immunocapture method for the application to soil samples containing high levels of clay particles and to utilize it for the isolation of Gluconacetobacter diazotrophicus strains from soil cultivated with sugarcane and coffee. The immunocapture technique was applied successfully for isolation of bacterium from soil samples. The modified immunocapture technique with $\mathrm{Al}_{2}\left(\mathrm{SO}_{4}\right)_{3}$ allowed the application of the method using clayed soil samples by the flocculation of the suspended clay. It proved to be effective for isolation of $G$. diazotrophicus inoculated in sterile sandy and clay soils five days after inoculation. The maximum sensitivity of the method to isolate $G$. diazotrophicus cells, using pure culture, was $10^{3}$ cells $\mathrm{mL}^{-1}$. The modification of the technique allows the capture of Gluconacetobacter spp. from soil samples near the coffee plants but not from sugarcane soils.
\end{abstract}

Index terms: immunology, ecology, sugarcane, coffee, diazotrophic bacterium.

\section{Introdução}

O uso de meios de cultivo é a base para o isolamento de bactérias, incluindo as diazotróficas. Meios de cultura sem adição de nitrogênio e com baixo teor de ágar (chamados de semi-sólido) separam de forma eficiente as bactérias diazotróficas de outros microrganismos. Várias bactérias foram isoladas utilizando o método do enriquecimento seletivo a partir da diluição e inoculação das amostras nestes meios de cultivo.

Quando se trata de amostras de solo, algumas espécies de bactérias são de difícil isolamento em virtude de freqüentemente se apresentarem em número inferior ao mínimo para detecção pela técnica ou pelo próprio estado nutricional.

Um bom exemplo desta dificuldade refere-se à espécie Gluconacetobacter diazotrophicus, que tem sido iso- lada apenas de amostras de órgãos vegetativos de plantas de cana-de-açúcar (Cavalcante \& Döbereiner, 1988; Reis et al., 1994), café (Jimenéz-Salgado et al., 1997), abacaxi (Tapia-Hernández et al., 2000), Pennisetum purpureum (Reis et al., 1994), insetos como as cochonilhas, que sugam a seiva de cana-de-açúcar (Franke et al., 1999), batata-doce (Paula et al., 1993) e outros cereais como Eleusine coracana (Loganathan et al., 1999). Entretanto, utilizando métodos clássicos de isolamento com meio semi-sólido, a bactéria não tem sido isolada de amostras de solos, mesmo de solo rizosférico de plantas hospedeiras (Reis et al., 1994). Além disso, em ensaios de inoculação, a sobrevivência no solo é muito baixa ou mesmo nula (Baldani et al., 1997). Apenas em amostras de café, foi possível o isolamento de estirpes presentes em solo da rizosfera, que pode ter pequenos fragmentos de raízes 
(Jimenez-Salgado et al., 1997). Estudos de inoculação usando solo natural ou autoclavado mostraram que essa espécie não era capaz de ser detectada após dois dias de inoculação (Baldani et al., 1997).

Anticorpos podem ser usados para o isolamento de microrganismos. A técnica de imunocaptura de bactérias foi desenvolvida por Mavingui et al. (1990) para o isolamento de Paenibacillus polymyxa de amostras de solo de rizosfera de trigo. Esta técnica consiste no uso de microplacas de poliestireno contendo 96 poços, como as usadas para a técnica de ELISA (Enzyme linked immunosorbent assay). As placas são cobertas com soro contra a bactéria de interesse, seguida da adição da amostra de solo. Após algumas etapas de incubação e lavagem, a ligação anticorpo-bactéria é quebrada pela adição de $\mathrm{KCl}$ 0,1 M. Os autores observaram que o número populacional de $P$. polymyxa no solo, sem a presença das raízes, era menor que $0,1 \%$ do número total de indivíduos. Com a aplicação de técnica de imunocaptura, a porcentagem de isolamento de P. polymyxa aumentou de $10 \%$ para $20 \%$ do total de isolados, obtendo-se 130 novos isolados a partir de amostras de solo sob rotação de milho, trigo e Brassica napus L. (Mavingui et al., 1992). Para aumentar o número de estirpes isoladas de Pseudomonas corrugata, a técnica de imunocaptura foi desenvolvida em conjunto com a utilização de meio de cultivo semi-seletivo para essa espécie (Achouak et al., 2000). A diversidade de $P$. corrugata foi maior no solo onde havia a rotação de milho com trigo do que em solos cultivados com milho durante 23 anos.

O método de imunocaptura tem como vantagem a rapidez de obtenção da estirpe, já que o soro captura a espécie de interesse e não as contaminantes, desde que seja espécie-específico. Desta forma, uma série de passos de purificação são eliminados, podendo-se alcançar uma economia de três semanas, no caso da purificação de G. diazotrophicus, mostrando a eficiência de isolamento por esta técnica, em relação às tradicionais, utilizando meio de cultivo.

Reis Junior (1998) usou a técnica de imunocaptura com algumas modificações para o isolamento de G. diazotrophicus de quatro amostras de raízes de plantas de cana-de-açúcar da variedade SP 701143 desenvolvida no campo. Com o uso da técnica, três isolados foram obtidos das quatro amostras avaliadas, ao passo que, por meio do método tradicional (meio de cultivo semi-sólido sem $\mathrm{N}$ ), não foi possível o isolamento desta espécie. Lebuhn et al. (2000) utilizaram esta técnica modificada - uso de tampão glicina para separação da bactéria acoplada ao soro - e isolaram estirpes de Ochrobactrum sp. de amostras de trigo desenvolvido em diferentes tipos de solo.

Outra técnica imunológica aplicada na captura de isolados bacterianos presentes no ambiente refere-se ao uso de partículas magnéticas cobertas com o soro de interesse. O método baseia-se na informação de que um tipo de célula pode ser selecionado de uma mistura heterogênea de células bacterianas pela atração específica produzida pelo anticorpo e a célula alvo. Os grânulos de metal são atraídos para um magneto, permitindo a lavagem e separação desses grânulos (Dye, 1994). Christensen et al. (1992) utilizaram esta técnica para recuperar bactérias redutoras de sulfato de amostras de óleo e água do mar. Han \& New (1998) adaptaram essa técnica magnética para o isolamento de estirpes de Azospirillum a partir de amostras de solo.

O objetivo deste trabalho foi aplicar a técnica de imunocaptura para o isolamento da espécie G. diazotrophicus a partir de amostras de solo de diferentes áreas de cultivo de cana-de-açúcar situadas no Estado do Rio de Janeiro e São Paulo e de amostras de solo cultivado com café.

\section{Material e Métodos}

Soro policlonal contra a estirpe padrão $\mathrm{PRJ}^{\mathrm{T}}$ (AsPRJ2) de G. diazotrophicus foi obtido por meio da imunização de coelhos Nova Zelândia de dois meses de idade. A estirpe foi obtida da Coleção de Bactérias Diazotróficas da Embrapa Agrobiologia (no BR 11200). Células intactas foram usadas para imunização após o desenvolvimento em $50 \mathrm{~mL}$ de meio Dygs contendo, em $\mathrm{g} \mathrm{L}^{-1}$ : glucose, 2,0; peptona, 1,5; extrato de levedura, 2,0; $\mathrm{K}_{2} \mathrm{HPO}_{4}, 0,5 ; \mathrm{MgSO}_{4} .7 \mathrm{H}_{2} \mathrm{O}$, 0,5; e ácido glutâmico, 1,5, pH 6,0 e desenvolvidas por 12 horas. A suspensão celular foi centrifugada a $3.500 \mathrm{~g}$ e o sobrenadante descartado. O precipitado foi ressuspendido em $2 \mathrm{~mL}$ de $\mathrm{NaCl}$ (1\%) após a inativação das células em água fervente por 90 minutos (células mortas). A imunização foi subcutânea, usando $100 \mathrm{~mL}$ da suspensão injetada em oito pontos diferentes do corpo do coelho e injeções subseqüentes no músculo da coxa do coelho foram repetidas aos 14, 21, 28, 42 e 47 dias, sendo então feita a pulsão cardíaca para obtenção de $50 \mathrm{~mL}$ de sangue (Reis et al., 2000). O plasma foi transferido para tubos Eppendorf, centrifugados a $4^{\circ} \mathrm{C}$ por 10 minutos a $10.000 \mathrm{~g}$ para remover as partículas sólidas presentes, 
como hemáceas. Depois dessa etapa, apenas o sobrenadante foi recolhido, transferido para novos tubos Eppendorf, onde sofreu tratamento térmico a $56^{\circ} \mathrm{C}$ por 30 minutos a fim de inativar as proteínas do sistema complemento. Ao final, alíquotas de $1 \mathrm{~mL}$ do soro foram transferidas para frascos de vidro estéreis e armazenadas a $-20^{\circ} \mathrm{C}$.

O imunoensaio de ELISA indireto foi utilizado para o título, caracterização de reações cruzadas e número mínimo de células necessário para a detecção. O soro foi testado contra diversas estirpes de bactérias diazotróficas, conforme descrito por Schloter et al. (1997), utilizando placas de poliestireno contendo 96 poços (Hemobag, Brasil). Foram utilizadas três repetições por estirpe e o ensaio, repetido três vezes. As estirpes testadas foram: G. diazotrophicus (PRJ2, PPE4, PAL5T e PAL3), G. johannae (CFN-cf55 ${ }^{\mathrm{T}}, \mathrm{CFN}-\mathrm{cf50}$, CFN-cf51 e CFN-cf52), G. azotocaptans (CFN-ca97 e CFN-cf58) - novas espécies de Gluconacetobacter descritas por Fuentez-Ramirez et al. (2001) -, Herbaspirillum seropedicae (Z67T e HRC80), H. rubrisubalbicans (M4 ${ }^{\mathrm{T}}$ ), Burkholderia sp. (M130, M212 e ERA32), B. tropica (PPE8 $\left.{ }^{\mathrm{T}}\right)$, Azospirillum amazonense (Y6 ${ }^{\mathrm{T}}$ e CBAMC) e A. brasilense (Sp31 e Sp245). Todas as estirpes cresceram em meio Dygs líquido por 12 horas a $30^{\circ} \mathrm{C}$. As células foram centrifugadas a $10.000 \mathrm{~g}$ por 5 minutos e ressuspendidas em tampão carbonato-bicarbonato. A suspensão celular foi ajustada para $\mathrm{DO}_{560}=1,0$ contendo $10^{8}$ células $\mathrm{mL}^{-1}$.

A técnica de imunocaptura consistiu da utilização de placas de ELISA cobertas com $200 \mu \mathrm{L}$ de solução de proteína A - 1 mg, diluída em tampão carbonato-bicarbonato $\left(80 \mathrm{~mL}\right.$ de $\mathrm{NaHCO}_{3} 0,2 \mathrm{M} \mathrm{e} 100 \mathrm{~mL}$ de $\mathrm{Na}_{2} \mathrm{CO}_{3}$ $0,2 \mathrm{M}, 1: 50 \mathrm{p} / \mathrm{v})-$, mantidas na geladeira $\left(4^{\circ} \mathrm{C}\right)$ por uma noite (16-18 horas). A seguir, as placas foram lavadas com tampão PBS pH 7,2 contendo 0,05\% de Tween 20 e $0,5 \%$ de albumina bovina (solução de lavagem). Depois da lavagem, adicionaram-se $200 \mu \mathrm{L}$ do anticorpo As-PRJ2 diluído 1:1.000 (v/v) (após teste de diluição do anticorpo secundário) em PBS 1:10 (v/v) e procedeuse à incubação por uma hora a $37^{\circ} \mathrm{C}$, mantendo-se a placa sob suave agitação (aproximadamente $60 \mathrm{rpm}$ ), utilizando mesa rotativa própria para placas de ELISA. A lavagem foi realizada por mais duas vezes, utilizando a solução descrita. A seguir, foram aplicados $200 \mu \mathrm{L}$ de suspensão de solo em cada poço e a placa incubada a $37^{\circ} \mathrm{C}$ durante 2 horas. A partir desse estágio, todo o procedimento é realizado em ambiente estéril, utilizando capela de fluxo laminar. As placas foram lavadas cinco vezes, utilizando a solução de lavagem filtrada em filtro Millipore $(0,2 \mu \mathrm{m})$. Para realizar a digestão do anticorpo, visando a separação da bactéria, foram aplicados $200 \mu \mathrm{L}$ de papaína diluída 1:50 (p/v) em tampão papaína preparado com 2,6 mL da solução A (cisteína 50 mM) e 2,6 mL da solução B (NaEDTA $10 \mathrm{mM}$ ), volume final completado para $50 \mathrm{~mL}$ com água estéril e pH ajustado para 6,2. A placa foi incubada por uma hora sob baixa agitação. A seguir, o conteúdo de cada poço foi adicionado a $5 \mathrm{~mL}$ de meio de cultivo semi-sólido LGI-P, descrito por Reis et al. (1994) e semi-seletivo, para o isolamento de G. diazotrophicus, utilizando quatro repetições (50 $\mu \mathrm{L}$ por vidro).

O procedimento de preparo da amostra com sulfato de alumínio foi aplicado a partir de $200 \mathrm{~g}$ de solo coletado de áreas plantadas com cana-de-açúcar e café. As amostras foram colhidas a $20 \mathrm{~cm}$ de profundidade e em dois locais, a 50 cm e a $3 \mathrm{~m}$ de distância das plantas, sendo as amostras mais distantes usadas para avaliar a população sem a influência da raiz. As coletas foram realizadas na Estação Experimental da Embrapa Agrobiologia em Seropédica, RJ, e na Copersucar (Cooperativa dos Produtores de Cana, Açúcar e Álcool do Estado de São Paulo), em Piracicaba e Jaú, SP. Os resíduos de plantas foram removidos antes da coleta das amostras. Também foi feita a coleta de amostras de café plantado no campus da Universidade Federal Rural do Rio de Janeiro, Seropédica, RJ. As características físicas dos solos avaliados estão descritas na Tabela 1.

Cada amostra de solo contendo $10 \mathrm{~g}$ de solo foi peneirada e pedaços de raízes foram retirados com o auxílio de uma pinça. Dos $10 \mathrm{~g}$ coletados, $5 \mathrm{~g}$ foram separados e misturados em $45 \mathrm{~mL}$ de água destilada estéril. A seguir, adicionou-se $0,5 \mathrm{~g}$ de resina Chelex 100 e 0,5 g de polietilenoglicol PEG 6.000 e a mistura foi mantida sob agitação a $150 \mathrm{rpm}$ a $4^{\circ} \mathrm{C}$ durante 30 minutos. Esta suspensão foi filtrada em filtro Melitta no 103. Para remover parte da argila, utilizaram-se $5 \mathrm{mg}$ de $\mathrm{Al}_{2}\left(\mathrm{SO}_{4}\right)_{3}$. A mistura ficou descansando por 30 minutos à temperatura ambiente e o material floculado (15 mL) foi filtrado em filtro Millipore de $5 \mu \mathrm{m}$. $\mathrm{O}$ material foi centrifugado a $10.000 \mathrm{~g}$ a $10^{\circ} \mathrm{C}$, durante 10 minutos. O material precipitado foi ressuspendido em $1 \mathrm{~mL}$ de tampão PBS e adicionado aos poços da microplaca para o procedimento da imunocaptura. 
Para determinar a sensibilidade do método, a estirpe PRJ2 foi inoculada em meio SYP líquido (CaballeroMellado \& Martinez-Romero, 1994), incubada por 18 horas e a concentração final de células foi ajustada para $\mathrm{DO}_{436}=0$,9. Esta absorbância resulta em aproximadamente $2,8-3,3 \times 10^{8}$ células $\mathrm{mL}^{-1}$. Uma diluição serial (1/10) da concentração final de células foi efetuada, até a concentração de 2,8-3,3x10 células $\mathrm{mL}^{-1}$ e, de cada diluição, foi retirado $1 \mathrm{~mL}$, então adicionado a $5 \mathrm{~g}$ de solo Oxisol de Jaú e uma amostra do Planossolo (horizonte A) coletado em Seropédica, peneirados e esterilizados duas vezes em autoclave, com intervalos de 24 horas entre cada autoclavagem. Os frascos contendo a mistura de solo e bactéria foram incubados à temperatura ambiente e a técnica de imunocaptura foi aplicada para isolar a bactéria durante cinco dias consecutivos.

Um novo ensaio foi realizado para avaliar a recuperação de células de $G$. diazotrophicus inoculadas em diferentes tipos de textura de solo. Duas amostras dos solos apresentadas na Tabela 1 foram utilizadas uma de solo argiloso coletado em Jaú (amostra 3) e outra de solo arenoso coletado em Seropédica, RJ (amostra 11). O solo foi limpo para retirar pedaços de raízes e resíduos vegetais e autoclavado duas vezes em intervalos de 24 horas. Copos de plástico de $15 \mathrm{~mL}$ foram usados para a inoculação, conforme descrito (mesma densidade ótica) e o solo foi testado com adição de $1 \%$ de glicose (de acordo com o peso do solo seco), visando manter as células viáveis. Os copos de plástico foram preenchidos com 20 g de cada amostra de solo com três repetições para cada dia de avaliação. A inoculação foi realizada

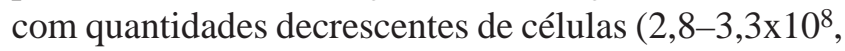
$10^{6}, 10^{5}, 10^{4}, 10^{3}, 10^{2}$ células $\left.\mathrm{mL}^{-1}\right)$, mantidas à temperatura ambiente, sendo a umidade controlada durante todo o ensaio. $\mathrm{O}$ controle recebeu apenas água destilada estéril. $\mathrm{O}$ isolamento da estirpe PRJ2 foi feito por meio do método de imunocaptura descrito.
Os isolados obtidos das amostras de solo avaliadas foram caracterizados utilizando a técnica de ELISA indireto, de acordo com Schloter et al. (1997), utilizando o anticorpo As-PRJ2 para indicar se o isolados pertenciam ao gênero Gluconacetobacter spp. Embora não possamos afirmar a espécie do isolado com apenas este método, a caracterização morfológica também foi realizada, utilizando meio de cultivo semi-sólido e sólido, conforme descrito por Reis et al. (1994). Cada isolado foi desenvolvido em meio Dygs por 18 horas, e as células foram coletadas por centrifugação (10.000 $\mathrm{g}$ por $10 \mathrm{mi}-$ nutos), descartado o sobrenadante e o precipitado ressuspendido em tampão carbonato-bicarbonato com a $\mathrm{DO}_{436}=0,9$.

\section{Resultados e Discussão}

O soro As-PRJ2 apresentou reação cruzada contra outros gêneros em valores menores que $45 \%$ (Figura 1). O soro As-PRJ2 compartilhou cerca de $41 \%$ dos determinantes antigênicos (epitopos) com a estirpe M212 e 31\% com a estirpe ERA32, ambas caracterizadas como Burkholderia sp., além de 34\% com Azospirillum amazonense estirpe CBAMC e 21\% com a estirpe Y6 $6^{\mathrm{T}}$. Contra outras estirpes pertencentes ao gênero Gluconacetobacter - G. johannae e G. azotocaptans (Fuentes-Ramírez et al., 2001) -, foi observado pelo menos 35\% de reações cruzadas, e contra os isolados de G. johannae (CFN-cf50, CFN-cf51, CFN-cf52 e CFNcf53), foi obtido mais que $100 \%$ de reação cruzada, com exceção do isolado CFN-ca54, que obteve valores inferiores a $10 \%$ (Figura 2 ).

Antes da aplicação de $\mathrm{Al}_{2}\left(\mathrm{SO}_{4}\right)_{3}$, não era possível obter uma amostra limpa, sem partículas de argila em suspensão, mesmo com a passagem da solução de solo pelo filtro de $5 \mu \mathrm{m}$. Essa argila em suspensão impedia que o soro atraísse a bactéria para uma acoplagem perfeita

Tabela 1. Análise granulométrica dos solos usados para imunocaptura ${ }^{(1)}$.

\begin{tabular}{|c|c|c|c|c|c|c|c|}
\hline Local & Cultura & Tipo de solo & Amostra & Areia & Silte & Argila & Textura \\
\hline \multirow{6}{*}{ Jaú, SP } & Cana-de-açúcar & LVE & 1 & 848 & 32 & 120 & Argiloso \\
\hline & & LVE & 2 & 840 & 32 & 128 & Argiloso \\
\hline & & LR & 3 & 466 & 134 & 400 & Barro-argiloso \\
\hline & & LVE & 4 & 314 & 206 & 480 & Barro \\
\hline & & TRE & 5 & 832 & 28 & 140 & Argiloso \\
\hline & & LVA & 6 & 720 & 110 & 130 & Argiloso \\
\hline \multirow[t]{4}{*}{ Piracicaba, SP } & Cana-de- açúcar & LVE & 7 & 770 & 100 & 120 & Argiloso \\
\hline & & LVE & 8 & 700 & 90 & 210 & Argiloso \\
\hline & & LVE & 9 & 700 & 90 & 210 & Argiloso \\
\hline & & LVE & 10 & 720 & 100 & 180 & Argiloso \\
\hline Seropédica, RJ & Cana-de-açúcar e café & Argissolo & 11 & 800 & 20 & 180 & Argiloso \\
\hline
\end{tabular}

${ }^{(1)}$ Valores em g kg-1; LVE: Latossolo Vermelho-Escuro; LR: Latossolo Roxo; TRE: Terra Roxa Estruturada; LVA: Latossolo Vermelho-Amarelo. 
e muitas células eram perdidas durante o processo de lavagem (solo inoculado). Desta forma, a técnica não funcionou em amostras com elevados teores de argila e apenas em solos de texturas arenosas era possível usar o procedimento sem a etapa de aplicação do sulfato de alumínio. Depois da adição do agente floculante $\left(\mathrm{Al}_{2}\left(\mathrm{SO}_{4}\right)_{3}\right)$, foi possível detectar células até a diluição de $10^{3}$ células $\mathrm{mL}^{-1}$, utilizando solo de Jaú e Seropédica. Nos dois solos, foi possível a captura e o isolamento da bactéria inoculada durante os cinco dias de ensaio; principalmente na presença de glicose, o isolamento foi possível com até 100 células por copinho (Tabela 2). De acordo com Kennedy (1999), a população total de bactérias no solo pode variar de $10^{4}$ a $10^{9}$ células g- $^{-1}$ de solo. Li \& MacRae (1992) quantificaram a população de G. diazotrophicus na rizosfera como de $2,3-5,7 \times 10^{6}$ células g-1 de solo seco. Entretanto, quando estes autores tentaram quantificar a população de G. diazotrophicus presente no solo, usando o método de ELISA, esses números ficaram abaixo do limite de detecção. Usando o método do número mais provável e o meio de cultivo contendo sacarose e extrato de levedura (pH 6,5), descrito por Li \& MacRae (1991), a po-

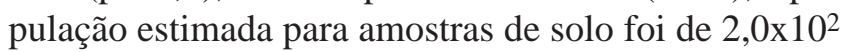

até $1,8 \times 10^{4}$ células g-1 $^{-1}$ de solo seco. O método de imunocaptura apresentado estende o limite de detecção até 1.000 células $\mathrm{g}^{-1}$ de solo, índice superior ao obtido quando utilizado meio de cultivo, que pode variar de 100 a 1.000 células $\mathrm{g}^{-1}$ de solo, dependendo da bactéria. A vantagem do procedimento imunológico é o isolamento direto da bactéria alvo ou mesmo do gênero, de acordo com a qualidade do anticorpo.

Entretanto, mesmo depois da adição de alumínio em uma das etapas da técnica de imunocaptura, não foi possível obter isolados de Gluconacetobacter dos solos plantados com cana-de-açúcar. Uma das características descritas das bactérias endofíticas é a baixa sobrevivência no solo e isto, provavelmente, é um fator que previne o isolamento de G. diazotrophicus de solos cultivados com cana-de-açúcar em condições tropicais. Outro fator pode ser a incapacidade de G. diazotrophicus de competir por fontes de carbono fora do tecido vegetal, como já descrito por Reis (1991). Este comportamento foi observado inoculando-se G. diazotrophicus com outra espécie de bactéria (competidor - táxon não identificado) em meio de cultivo. A bactéria diazotrófica tinha que exceder em 100 vezes a população da outra bactéria, para continuar a ser

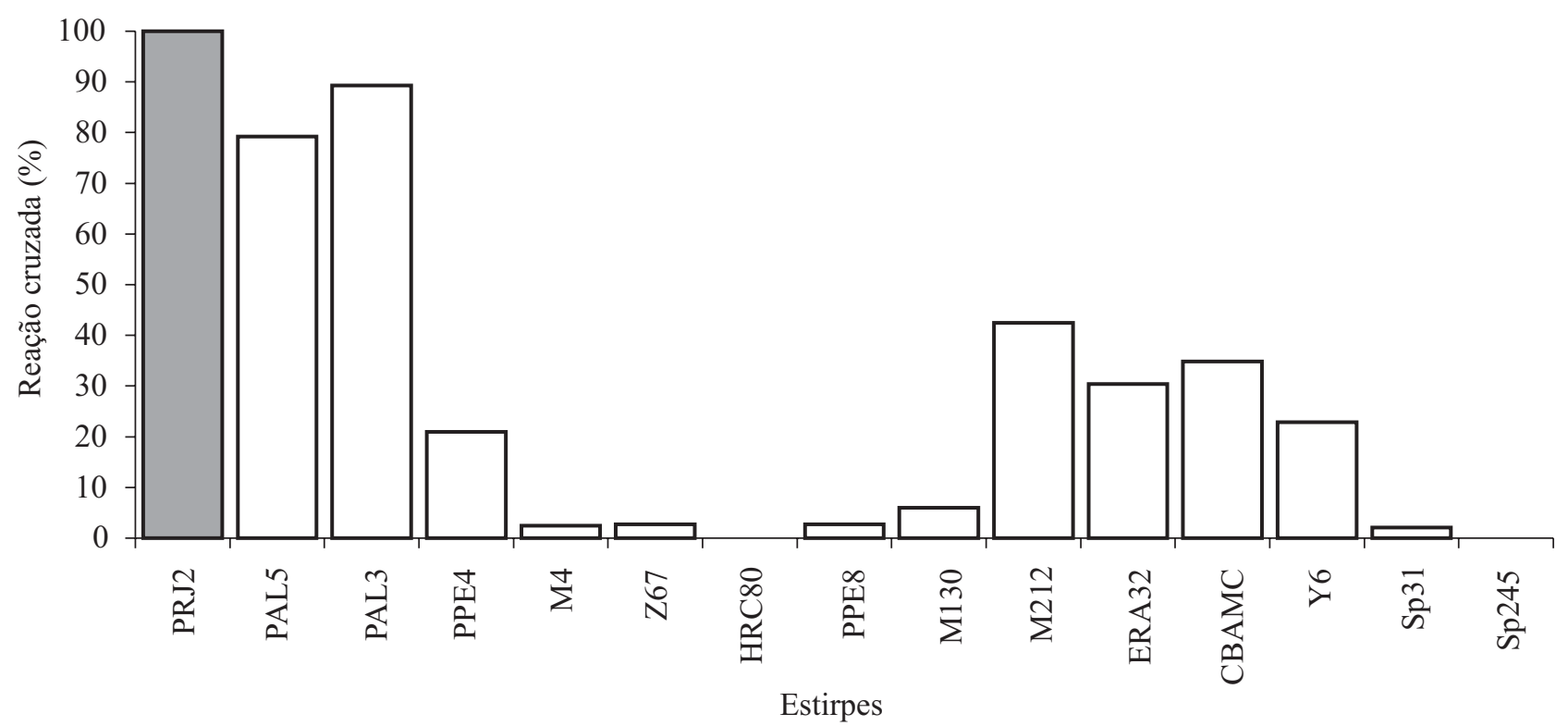

Figura 1. Reação cruzada entre o anticorpo As-PRJ2 contra estirpes de bactérias diazotróficas utilizando o imunoensaio de ELISA (\% de reação cruzada comparada a estirpe PRJ2 usada na imunização). Segundo conjugado acoplado a peroxidase e diluído 1:1.000 e tempo de reação da enzima com o substrato de 20 minutos. Estirpes testadas: G. diazotrophicus (PRJ2, PAL5, PAL3, PPE4), Herbaspirillum rubrisubalbicans (M4), H. seropedicae (Z67, HRC80), Burkholderia spp. (M130, M212, ERA32, PPE8), Azospirillum amazonense (CBAMC, Y6) e A. brasilense (Sp31, Sp245). 
detectada nos procedimentos de isolamento. Outra explicação para a dificuldade de isolar G. diazotrophicus de amostras de solo pode ser o limite de detecção de 1.000 células $\mathrm{g}^{-1}$ de solo, freqüentemente superior à sua população, conforme Li \& MacRae (1991). Outro fator refere-se à superfície celular, que pode ser alterada de acordo com as condições de solo, sofrendo modificações que poderiam afetar o reconhecimento do soro, desenvolvido a partir de bactérias desenvolvidas em meio rico. Isto foi evidenciado pelo aumento de dez vezes da captura de células inoculadas, quando se adicionou glicose à solução, nos dois tipos de solo. Por fim, a dificuldade em isolar G. diazotrophicus do solo pode estar relacionada ao fato de esta espécie não sobreviver no solo desnudo e, para isso, pode-se levar em consideração que esta espécie não use uma grande diversidade de fontes de carbono, tais como ácidos orgânicos e a maioria dos açúcares, ou ser pouco eficiente quanto ao uso destas, já que possui um metabolismo fermentativo (Stephan et al., 1991).

Thorne \& Williams (1997) enfatizaram que a qualidade, bem como a concentração de nutrientes, tem que ser considerada, quando se trabalha com a sobrevivência de células. Bashan (1999) mostrou que fatores do solo, tais como a porcentagem de argila, nitrogênio, teor de matéria orgânica e capacidade de retenção de água são

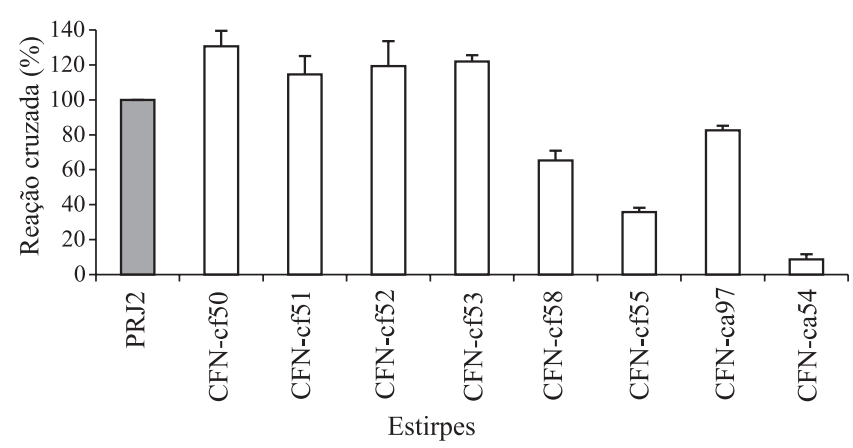

Figura 2. Reação cruzada entre o anticorpo As-PRJ2 contra estirpes de bactérias diazotróficas isoladas de café utilizando o imunoensaio de ELISA (porcentagem de reação cruzada comparada a estirpe PRJ2 usada na imunização). Segundo conjugado acoplado a peroxidase e diluído 1:1.000 e tempo de reação da enzima com o substrato de 20 minutos. As barras correspondem ao erro-padrão da média. Estirpes testadas: G. diazotrophicus (PRJ2), G. johannae (CFN-cf50, CFN-cf51, CFN-cf52, CFN-cf53, CFN-cf58, CFN-cf55), G. azotocaptans (CFN-ca97, CFN-ca54). positivamente associados à sobrevivência de Azospirillum, enquanto fatores como teor de carbonato, cálcio e areia influenciam negativamente esta população.

Foi possível isolar três estirpes do solo cultivado com café (ACcafé 1, 2 e 3), que podem pertencer ao gênero Gluconacetobacter, sugerindo a eficiência do procedimento utilizado (Figura 3). Estes isolados mostraram mais de 90\% de reação cruzada contra o soro As-PRJ2, o que sugere a sua classificação no gênero Gluconacetobacter, já que as outras espécies testadas não atingiram $50 \%$ de reações cruzadas. As três estirpes fixavam nitrogênio (reduziram acetileno), desenvolveram-se em meio de cultivo LGI-P e batata-P, mas não ficaram marrons. Embora a classificação do gênero não possa ser definitiva, os resultados sugerem que as estirpes pertençam ao gênero e que provavelmente sejam G. johannae, devido ao elevado valor de reação cruzada.

$O$ valor de reação cruzada alcançado entre as novas espécies de Gluconacetobacter descritas revelou um número que variou desde $17,5 \%$ até mais de $100 \%$ de epitopos contra a estirpe padrão PRJ2 usada na imunização (Figura 3). Estes valores, que podem chegar a $100 \%$ de compartilhamento, apontam para a possibilidade de, por meio da técnica proposta e em função das características do anti-soro utilizado, isolados de bactérias do gênero Gluconacetobacter serem obtidos a partir de amostras de solo cultivado com café. Jimenez-Salgado et al. (1997) isolaram várias estirpes de Gluconacetobacter de amostras de plantas de café e apenas uma foi isolada de caule (CFN-cf13) e duas de raízes (CFN-cf51 e CFN-cf52). Todas as outras estirpes foram isoladas da rizosfera de café. Este comportamento é completamente diferente do observado

Tabela 2. Efeito da adição de glicose $\left(5 \mathrm{~g} \mathrm{~L}^{-1}\right)$ na recuperação de células de $G$. diazotrophicus pelo método de imunocaptura, a partir de amostras de solo submetidas à inoculação de diferentes densidades populacionais e em dois tipos de solo, cinco dias depois da inoculação(1).

\begin{tabular}{lcccccccc}
\hline Tipo de solo & Glicose & \multicolumn{7}{c}{ Diluição serial de células da estirpe PRJ2 } \\
& & \multicolumn{7}{c}{$\left(\right.$ células $\left.\mathrm{mL}^{-1}\right)$} \\
\cline { 2 - 8 } & & $10^{8}$ & $10^{7}$ & $10^{6}$ & $10^{5}$ & $10^{4}$ & $10^{3}$ & $10^{2}$ \\
\hline \multirow{2}{*}{ LVE } & - & + & + & + & + & + & + & + \\
& + & + & + & + & + & + & + & + \\
\hline Planossolo & - & - & + & + & + & + & + & - \\
& + & + & + & + & + & + & + & + \\
\hline
\end{tabular}

(1)+: formação de crescimento positivo - película alaranjada na superfície e meio de cultivo LGI-P inoculado com alíquota final do procedimento de imunocaptura. -: sem formação de película. 


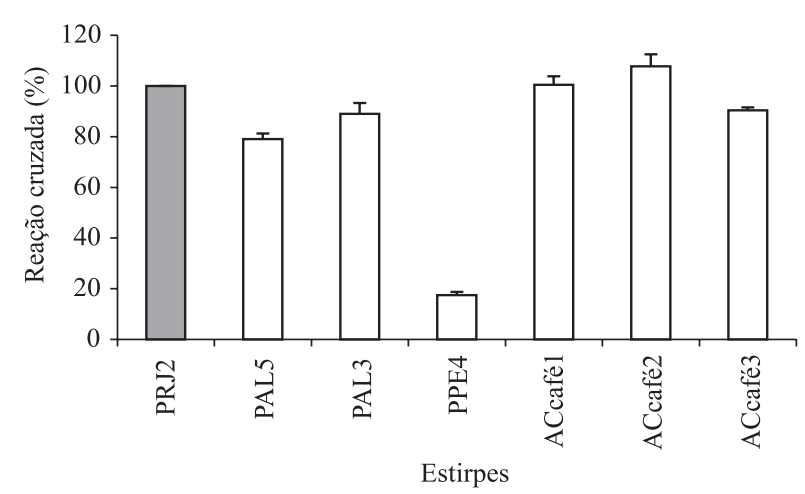

Figura 3. Reação cruzada de estirpes de Gluconacetobacter obtidas do solo cultivado com café (estirpes AC) e outras pertencentes à espécie G. diazotrophicus contra o anticorpo As-PRJ2. Segundo conjugado acoplado a enzima peroxidase e diluído 1:1.000 e tempo de reação do substrato da enzima de 20 minutos. ACcafé 1, 2 e 3 foram isoladas da mesma área de café mas de amostras de solo diferentes. As barras correspondem ao erro-padrão da média. G. diazotrophicus (PRJ2, PAL5, PAL3, PPE4).

com amostras de cana-de-açúcar, em que a maioria dos isolados foi obtida de amostras de raízes e parte aérea e raramente de rizosfera.

Estes resultados mostram a necessidade de se avaliar um número maior de amostras de solo, colhidas em épocas diferentes e comparar com amostras de solo da rizosfera e das raízes das plantas, a fim de verificar se a sobrevivência depende da presença da planta. Entretanto, com a modificação no procedimento de imunocaptura, não há mais limitação do tipo de solo onde a cultura for colhida.

\section{Conclusões}

1. A modificação no método de imunocaptura, pela adição de sulfato de alumínio, permite o uso dessa técnica para amostras de solos argilosos.

2. Não é possível isolar nenhuma estirpe de G. diazotrophicus das amostras de solo avaliadas.

3. Por meio da técnica de imunocaptura, é possível o isolamento de estirpes pertencentes ao gênero Gluconacetobacter de amostras de solo cultivado com café.

\section{Agradecimentos}

Ao CNPq, pela bolsa de mestrado concedida a Carla Cristiane Rocha dos Santos; à Capes, pela bolsa de dou- torado concedida a Liamara Perin; ao Programa de Apoio a Núcleos de Excelência (Pronex II), pelo suporte financeiro; à Faperj, pelo apoio.

\section{Referências}

ACHOUAK, W.; THIÉRY, J.M.; ROUBAUD, P.; HEULIN, T. Impact of crop management on intraspecific diversity of Pseudomonas corrugata in bulk soil. FEMS Microbiology Ecology, v.31, p.11-19, 2000.

BALDANI, J.I.; CARUSO, L.; BALDANI, V.L.D.; GOI, S.R.; DOBEREINER, J. Recent advances in BNF with non-legume plants. Soil Biology and Biochemistry, v.29, p.911-922, 1997.

BASHAN, Y. Interactions of Azospirillum spp. in soils: a review. Biology and Fertility of Soils, v.29, p.246-256, 1999.

CABALLERO-MELLADO, J.; MARTÍNEZ-ROMERO, E. Limited genetic diversity in the endophytic sugarcane bacterium Acetobacter diazotrophicus. Applied and Environmental Microbiology, v.60, p.1532-1537, 1994.

CAVALCANTE, V.A.; DOBEREINER, J. A new acid-tolerant nitrogen-fixing bacterium associated with sugarcane. Plant and Soil, v.108, p.23-31, 1988.

CHRISTENSEN, B.; TORSVIK, T.; LIEN, T. Immunomagnetically captured thermophilic sulfate-reducing bacteria from North Sea oil field waters. Applied and Environmental Microbiology, v.58, p.1244-1248, 1992.

DYE, M. The enrichment of Rhizobium from a model system using immunomagnetic separation. Journal of Microbiological Methods, v.19, p.235-245, 1994.

FRANKE, I.H.; FEGAN, M.; HAYWARD, C.; LEONARD, G.; STACKEBRANDT, E.; SLY, L.I. Description of Gluconacetobacter sacchari sp. nov., a new species of acetic acid bacterium isolated from the leaf sheath of sugar cane and from the pink sugar-cane mealy bug. International Journal of Systematic Bacteriology, v.49, p.1681-1693, 1999.

FUENTES-RAMÍREZ, L.E.; BUSTILLOS-CRISTALES, R.; TAPIA-HERNÁNDEZ, A.; JIMÉNEZ-SALGADO, T.; WANG, E.N.T.; MARTÍNEZ-ROMERO, E.; CABALLERO-MELLADO, J. Novel nitrogen-fixing acetic acid bacteria, Gluconacetobacter johannae sp. nov. and Gluconacetobacter azotocaptans sp. nov. associated with coffee plants. International Journal of Systematic and Evolutionary Microbiology, v.51, p.1305-1314, 2001.

HAN, S.O.; NEW, P.B. Isolation of Azospirillum spp. from natural soils by immunomagnetic separation. Soil Biology and Biochemistry, v.30, p.975-981, 1998.

JIMÉNEZ-SALGADO, T.; FUENTES-RAMÍREZ, L.E.; TAPIAHERNÁNDEZ, A.; MASCARUA-ESPARZA, M.A.; MARTÍNEZ-ROMERO, E.; CABALLERO-MELLADO, J. Coffea arabica L., a new host plant for Gluconacetobacter diazotrophicus and isolation of other nitrogen-fixing acetobacteria. Applied and Environmental Microbiology, v.63, p.3676-3683, 1997.

KENNEDY, A.C. Bacterial diversity in agroecosystems. Agriculture Ecosystems and Environment, v.74, p.65-76, 1999. 
LEBUHN, M.; ACHOUAK, W.; SCHLOTER, M.; BERGE, O.; MEIER, H.; BARAKAT, M.; HARTMANN, A.; HEULIN, T. Taxonomic characterization of Ochrobactrum sp. isolates from soil samples and wheat roots, and description of Ochrobactrum tritici sp. nov. and Ochrobactrum grignonense sp. nov. International Journal of Systematic and Evolutionary Microbiology, v.50, p.2207-2223, 2000.

LI, R.; MACRAE, I.C. Specific association of diazotrophic acetobacters with sugarcane. Soil Biology and Biochemistry, v.23, p.999-1002, 1991.

LI, R.; MACRAE, I.C. Specific identification and enumeration of Acetobacter diazotrophicus in sugarcane. Soil Biology and Biochemistry, v.24, p.413-419, 1992.

LOGANATHAN, P.; SUNITA, R.; PARIDA, A.K.; NAIR, S. Isolation and characterization of two genetically distant groups of Acetobacter diazotrophicus from a new host plant Eleusine coracana L. Journal of Applied Microbiology, v.87, p.167-172, 1999.

MAVINGUI, P.; LAGUERRE, G.; BERGE, O.; HEULIN, T. Genetic and phenotypic diversity of Bacillus polymyxa in soil and in the wheat rhizosphere. Applied and Environmental Microbiology, v.58, p.1894-1903, 1992.

MAVINGUI, P.; LAGUERRE, G.; BERGE, O.; HEULIN, T. Immunotrapping of Bacillus polymyxa in soil and in the rhizosphere of wheat. Symbiosis, v.9, p.215-221, 1990.

PAULA, M.A. de; SIQUEIRA, J.O.; DOBEREINER, J. Ocorrência de fungos micorrízicos vesículo-arbusculares e de bactérias diazotróficas na cultura de batata doce. Revista Brasileira de Ciência do Solo, v.17, p.349-356, 1993.

REIS, V.M. Aspectos ecológicos e fisiológicos da bactéria fixadora de $\mathbf{N}_{2}$ Acetobacter diazotrophicus. 1991. 91p. Dissertação (Mestrado) - Universidade Federal Rural do Rio de Janeiro, Seropédica.
REIS, V.M.; CRUZ, G.B.; REIS JUNIOR, F.B.; SALLES, J.F.; SCHLOTER, M. Characterization of different polyclonal antisera to quantify Herbaspirillum spp. in elephant grass (Pennisetum purpureum Schun.). Symbiosis, v.29, p.139-150, 2000.

REIS, V.M.; OLIVARES, F.L.; DOBEREINER, J. Improved methodology for isolation of Acetobacter diazotrophicus and confirmation of its endophytic habitat. World Journal of Microbiology and Biotechnology, v.10, p.401-405, 1994.

REIS JUNIOR, F.B. Influência do genótipo da planta, micropropagação e fertilização nitrogenada sobre a população de bactérias diazotróficas em cana-de-açúcar (Saccharum spp.). 1998. 154p. Dissertação (Mestrado) - Universidade Federal Rural do Rio de Janeiro, Seropédica.

SCHLOTER, M.; WIEHE, W.; ASSMUS, B.; STEINDL, H.; BECKE, H.; HOFLICH, G.; HARTMANN, A. Root colonization of different plants by plant-growth-promoting Rhizobium leguminosarum bv. trifolii R39 studied with monospecific polyclonal antisera. Applied and Environmental Microbiology, v.63, p.2038-2046, 1997.

STEPHAN, M.P.; OLIVEIRA, M.; TEIXEIRA, K.R.S.; MARTINEZDRETS, G.; DOBEREINER, J. Physiology and dinitrogen fixation of Acetobacter diazotrophicus. FEMS Microbiology Letters, v.77, p.67-72, 1991.

TAPIA-HERNÁNDEZ, A.; BUSTILLOS-CRISTALES, M.R.; JIMÉNEZ-SALGADO, T.; CABALLERO-MELLADO, J.; FUENTES-RAMÍREZ, L.E. Natural endophytic occurrence of Acetobacter diazotrophicus in pineapple plants. Microbial Ecology, v.39, p.49-55, 2000.

THORNE, S.H.; WILLIAMS, H.D. Adaptation to nutrient starvation in Rhizobium leguminosarum bv. phaseoli: analysis of survival, stress resistance, and changes in macromolecular synthesis during entry to and exit from stationary phase. Journal of Bacteriology, v.179, p.6894-6901, 1997.

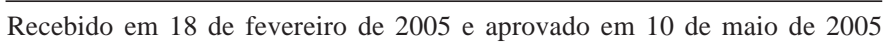

